\title{
(Post)human Temporalities: Science Fiction in the Anthropocene
}

\author{
Jonathan Hay \\ Ph.D. Candidate, University of Chester, UK \\ 1300404@chester.ac.uk
}

\begin{abstract}
Although many SF texts proceed from the speculative premise that our species will continue to develop technologically, and hence become increasingly posthuman, our species' continuance into even the next century is by no means assured. Rather, the Anthropocene exerts a new temporal logic; it is an age defined by an intensification of geological timescales. It is therefore noteworthy that many contemporary SF texts are ecologically interventionist and figure apocalyptic future temporalities which curtail the posthuman predilection common to the genre. This article analyses a tetrad of literary texts, written at various points during the last three decades, which summatively reveal the mutations of the (post)human temporalities figured by cli-fi texts. These four texts are: Kim Stanley Robinson's Mars Trilogy (1992-1996); Jeanette Winterson's The Stone Gods (2007); Michel Faber's The Book of Strange New Things (2014); and Paolo Bacigalupi's The Water Knife (2015).
\end{abstract}

\section{Keywords}

Anthropocene - Science Fiction - cli-fi - Critical Posthumanism

Whilst geological epochs typically last thousands of years, over the last three centuries our species has engineered a significant enough impact on the Earth to instigate an epoch geologically distinct from the Holocene. Thus, although the International Commission on Stratigraphy (ICS) continues to prefer the term Holocene, the popular term Anthropocene becomes an increasingly more accurate classification of our present geological epoch with each day that passes. Although some scholars argue for an earlier onset of the 
Anthropocene epoch, the term was coined in the year 2000 by Paul J. Crutzen and Eugene F. Stoermerto, who define the Anthropocene as the rapid intensification of our species' adverse impact upon our host planet, which has been particularly evident since roughly the "invention of the steam engine in 1784 " (17-18).

The term Anthropocene is no expression of hubris, however, but rather a damning acknowledgement of the planetary changes prompted by our species' unqualified failure to sustain a mutualistic interaction with the Earth. The repercussions of Anthropogenic climate change will imperil the continuation not only of our own species but also, in the long-term, the viability of the vast proportion of all life on Earth. Even since the beginning of 2019, scholarship on the Anthropocene has dealt with subject matters as diverse as Anthropocene politics, the role of poetry in the Anthropocene, and the provisional nature of architecture in the Anthropocene (John S. Dryzek and Jonathan Pickering's The Politics of the Anthropocene (2019), David Farrier's Anthropocene Poetics (2019), and Renata Tyszczuk's Provisional Cities (2019), respectively). The riotously interdisciplinary nature of the field of Anthropocene scholarship deftly reflects the all-encompassing nature of the planetary changes that are driving the epoch.

In his 2019 book The Uninhabitable Earth, David Wallace-Wells laments that, incredibly, since the beginning of the 1990s, our species has collectively "done as much damage to the fate of the planet and its ability to sustain human life and civilization [...] than in all the centuries - all the millennia - that came before" (4). Beyond our own lifetimes, it will be the damage we have wrought on the Earth's ecosystems that will stand as the perverse legacy of modern societies. The Anthropocene is concurrently a hyperobject-as Timothy Morton proposes in his 2013 work of the same name-which "spell[s] the end of environmentalisms that employ Nature" as a valid ontological category (199). Likewise, in their 2015 essay "Preface to a Genealogy of the Postnatural," Richard W. Pell \& Lauren B. Allen propose the term "postnatural" in order to better reflect the plethora of "anthropogenic interventions into evolution that are both intentional and heritable" and that have always characterised the interactions between our species and planet (79, emphases in original). Ecological discourses in the Anthropocene must therefore define our planet's environmental circumstances as postnatural, in order to reject dichotomous thought processes which posit a distinction between our species and the purportedly natural world. Likewise, as Elizabeth Kolbert notes in her 2014 book The Sixth Extinction, globalisation is effectively "running geologic history backward and at high speed" and has now become a far greater influence than millions of years of tectonic drift on the dispersal of species worldwide (208). The drastic 
acceleration of planetary history—along with the need to deconstruct the presumptions of many of our species' most established ontological models-is the terrifying new temporal logic of the Anthropocene.

Indeed, as Wallace-Wells notes, "we might better conceive of history not as a deliberate procession of years marching forward on a timeline but as an expanding balloon of population growth" $(2019,8)$. By inaugurating population growth as the decisive temporal metric of the Anthropocene, it becomes newly apparent that our species' detrimental impact upon the Earth is not a gradual process but an inevitable and near-exponential trend. In this manner, social development can no longer be considered a mode of progress because it leads not to a telos (an Ancient Greek term for a determinate end or purpose) but to catastrophe. This abrupt schism in the logic of progress, formerly the overriding metanarrative of our species, is already reflected in a range of contemporary art; yet, as Wallace-Wells emphasises, although "[o]n-screen, climate devastation is everywhere you look," it is rarely a central premise of these same fictional narratives $(2019,143)$. Likewise, as George Marshall states in his 2014 book Don't Even Think About It, "science fiction fans of all people, [are] so unwilling to imagine what the future might really be like" (2). Although this is largely accurate, Marshall's insinuation that the entire SF genre fails to imagine the future in realistic terms is certainly mistaken.

I nevertheless agree with Marshall's implicit assertion that Science Fiction (henceforth SF) has long proceeded from the speculative premise that our species will continue to develop technologically. In his 2009 essay "SF Tourism," Brooks Landon stresses that SF's tendency of "constructing change as progress, and seeing science and technology as its driving force [are] central aspects of sf thinking" (34). Crucially however, there is significant evidence that the onset of the Anthropocene has more recently rendered the genre's teleological orientation problematic. Indeed, within the contemporary SF genre, apocalyptic representations of climate change are particularly abundant, and this trend challenges the assumption that our species will continue to become increasingly technologically advanced.

It therefore proves productive to read this contemporary wave of SFwhich can be termed climate fiction (or cli-fi for short) - in conversation with the philosophical field of Critical Posthumanism. In her 1999 monograph How We Became Posthuman, N. Katherine Hayles states that "As we rush to explore the new vistas that cyberspace has made available for colonization, let us remember the fragility of a material world that cannot be replaced" (49). As a means of definition, Hayles argues that "[a]lthough the 'posthuman' differs in its articulations, a common theme is the union of the human with the intelligent machine" $(1999,2)$. In concord with her contention that technological and 
social progress are inextricably "seriated" $(1999,20)$, this article refers to our species as (post)humanity, and to our condition as being (post)human, supposing that we currently inhabit an intermediary stage between being human and posthuman. Although I have elsewhere proposed that SF texts generally theorise a dreamscape of "posthuman possibility" (see Hay 2019), it is pertinent to note that many modern SF texts are ecologically interventionist and curtail the posthuman dreamscape common to the genre by emphasising the apocalyptic temporal attributes of the Anthropocene epoch in our own time. Hence, as Hayles also recognises, the figure of the posthuman is a possibility entirely conditional upon (post)humanity's achieving modes of symbiosis with its planetary environment.

By foregrounding the necessity for human societies to fast become less beholden to habitual patterns of environmental apathy, the diegetic societies of cli-fi texts such as the 2009 film The Age of Stupid, the 2016 Black Mirror episode "Hated in the Nation," Cormac McCarthy's The Road (2006), and Margaret Atwood's Maddaddam Trilogy (2003-2013) dramatise the annihilation of the everyday. As Heather J. Hicks proposes in her 2016 work The Post-Apocalyptic Novel in the Twenty-First Century, such texts carry a "sense of inevitable change, imagining a move not to new lands, but to new times, with no return passage possible" (103). As Pramod K. Nayar asserts is true of Posthumanism in his 2014 book of the same name, cli-fi does not endeavour to ideologically reinscribe "the human as exceptional, separate from other life forms and usually dominant/dominating over these other forms." Rather, whilst engaging imaginatively with the dystopian milieux of cli-fi texts, (post)human readers can no longer delude themselves that they are exceptional beings (4). As cli-fi's deliberate interruption of the SF genre's posthuman dream implies, if our species does not make vast progress towards attaining environmental symbiosis, a large portion of our species will not even survive into the next century.

Cli-fi texts, therefore, solicit their reader to consider the alarmingly default possibility that our species may not attain symbiosis with its environment rapidly enough to circumvent apocalyptic consequences. In his 1979 work Metamorphoses of Science Fiction, Darko Suvin states that "SF is distinguished by the narrative dominance or hegemony of a fictional 'novum' (novelty, innovation)" (63, emphasis in original), or, in many instances, by multiple nova. Hence, if it remains true that — as Tom Shippey asserts in his 2016 work Hard Reading - "science fiction depends on novelty" (27), then cli-fi texts are certainly defined by a very atypical variety of novelty; their SFnal (sciencefictional) nova work to elicit the reader to undertake a sustained reflection upon their own damaging and yet habitualised methods of interaction with their environment. Accordingly, cli-fi narratives are typically attuned towards 
the environmental surroundings of their texts' diegetic worlds, which are shown to imperil and hence condition the continued existence of any nova. Thus nova become habitual entities comparatively, directly inverting the typified relationship between the novum and its mundane environment in the existing body of science fiction.

Cli-fi texts often exacerbate the tendency of the genre towards what Suvin recognises as an inherent "anthropological pessimism" (1980, 236); their ecological pessimism has a powerful didactic utility. In contrast to the "resonances and charms of Big Dumb Objects" — a term coined by Roz Kaveney in her 1981 article "Science Fiction in the 1970s" — with which the SF genre is characteristically obsessed, cli-fi novels are principally concerned with the Small Dumb Objects that (post)humans themselves are (25). Through the analysis of four cli-fi texts, this study argues that SF focussed on the Anthropocene comprises an invaluable tool for coming to terms with the future of our planet. The four texts studied are: Kim Stanley Robinson's Mars Trilogy (1992-1996), Jeanette Winterson's The Stone Gods (2007), Michel Faber's The Book of Strange New Things (2014), and Paolo Bacigalupi's The Water Knife (2015). All these texts were written during the last three decades by European and American authors. This article reads this cross-section of representative cli-fi novels chronologically, in order to reveal the rapidly mutating elements of the Western outlook on climate change over even this short period of the Anthropocene epoch.

\section{$1 \quad$ The Mars Trilogy}

Written and released during the 1990s, the temporally expansive narrative scope of Kim Stanley Robinson's Mars Trilogy is ostensibly similar to several great canonical SF series, such as Isaac Asimov's Greater Foundation series or Ursula K. Le Guin's Hainish Cycle. Yet on closer inspection, the Trilogy actually works to deconstruct the escapist underpinnings of such prior SF works. Red Mars (1992) documents the colonisation of a neighbouring planet by a number of (post)humans; Green Mars (1993) narrates their continuing efforts to terraform that planet; and Blue Mars (1996) concludes as Mars becomes a liveable environment for its colonisers and their offspring almost two hundred years after its colonisation first began. By satirising his readers' desire to read SF which escapes their own temporality, Robinson makes it clear that it is critical they begin to prioritise their attitude towards their planetary environment in their present.

Although its opening line is "Mars was empty before we came. [...] We are all the consciousness that Mars has ever had," the error of such neo-colonialist 
ideologies is rigorously challenged throughout the Mars Trilogy (Robinson, Red Mars, 13). At the series' outset, this line of dialogue posits an exceedingly anthropocentric appraisal of Mars, envisioning that (post)humans have an entitlement akin to manifest destiny to settle their neighbouring planet, a planet which has only gained any degree of consequence by virtue of their settlement of it. The narratorial persona which voices this retrospective entirely fails to recognise that - as Erika Cudworth and Stephen Hobden emphasise in their 2011 book Posthuman International Relations - because "Humans neither exist, nor have they developed, independently of other animate and inanimate systems," they will always remain interrelated within the stochastically complex systems which comprise any planetary environment (187).

The first settlers of Mars in the Trilogy choose to artificially regulate the Martian day, a feat brought about by "the Martian time-slip, the thirty-nine and a half minute gap between 12:00:00 and 12:00:01, when all the clocks went blank or stopped moving" (Robinson, Red Mars, 33). The re-imposition of the familiar diurnal round not only brings an illusory sense of naturalness to their inhabitation of the alien planet, but also allows the (post)humans inhabiting Mars to approximate habitual sleep patterns and hence to begin to re-establish society, which is itself undergirded by the habitual. Nevertheless, the settlers perceive that "something in the slant and redness of the light was fundamentally wrong"-Mars' marginally different visible light spectrum being enough to upset "expectations wired into the savannah brain over millions of years" (Robinson, Red Mars, 25). This passage emphasises just how irregular it is for our species to have ever had the need to inhabit Mars as a surrogate Earth, reminding readers that we will never find another planet that is as suited to our species' idiosyncrasies as Earth is, since we evolved here and thus are highly adapted to living here.

Correspondingly, it is only midway through the second book of the Mars Trilogy that (post)humans are finally able to brave the Martian atmosphere and get "their clothes off" outside of settlements or buildings (Robinson, Green Mars, 432). Although Mars is perceived as a chance to start again, a "blank red slate" for the crew of the Ares to write upon, it is a tabula rasa which proves challenging to inscribe (Robinson, Red Mars, 108). After landing, "for day after day after day [there is] No change in the weather to speak of." To disrupt this monotonous trend, the first Martians find it necessary to thicken the atmosphere in order to gradually make the planet more Earth-like and hence more conducive to (post)human life (Robinson, Red Mars, 135). Although many (post)humans on both Mars and Earth disagree with this course of action, many other groups with an interest in Mars desire the planet to become a facsimile of Earth, through a process of terraforming effected through methods 
which include the creation of an aerial lens that makes "the light some twenty percent greater than before" (Robinson, Green Mars, 179).

It is deeply ironic that, years after Mars has first been settled, the (post) humans back on Earth are fast "running out of oil" and so start "mining and oil drilling" in Antarctica (Robinson, Red Mars, 298). Transnational corporations from Earth soon attempt to lay a claim on Mars, and call for it to be further terraformed under the rationale that "we're all colonies now" (Robinson, Red Mars, 46o). As Robinson makes plain at this point and throughout the Trilogy, capitalist and ecological modes of thought utterly contradict each other. Yet as Cudworth and Hobden highlight, "the state system, global capitalism, the agricultural system and the biosphere" $(2011,108)$ have all emerged through a process of autopoetic co-evolution, and so these phenomena are not individually mutable, but rather invariably anastomotic as formations emergent from (post)human societies.

Whilst the great flood that decimates large parts of Earth in the Mars Trilogy is not caused by anthropogenic climate change, and instead by "a cluster of violent volcanic eruptions under the West Antarctic ice sheet," it is exacerbated by the effects of (post)human overpopulation which has, by the year 2128, far exceeded Earth's carrying capacity (Robinson, Blue Mars, 167). The colonists of Mars are soon overwhelmed by immigrants from Earth fleeing the effects of anthropogenic overpopulation, as Mars is eulogised as a way of "saving Earth from overpopulation with the gift of empty land" (Robinson, Blue Mars, 346). As Cudworth and Hobden emphasise, even beyond our direct influence upon our climate, "Human systems are embedded within a number of non-human systems, with the consequence that developments in one system may have implications elsewhere in the panarchy" $(2011,138)$.

Eventually, the (post)humans of Mars have lived on Mars for so long, and their cultures have diverged so far from those of their originary planet, that the chance to see Earth would be "So interesting that no rational person could pass up the opportunity" (Robinson, Blue Mars, 109). Accordingly, 102 years after the Ares mission departed Earth, a small number of the crew and their descendants return briefly as ambassadors for Mars. As a (post)human born on Mars, Nirgal's acute feeling of euphoria at his first experience of Earth is palpable. Able to distinguish "Fifty different shades of green on the hills" for the first time in his life, he experiences sensory overload, and finds the natural beauty and enormity of Earth incredibly overbearing (Robinson, Blue Mars, 175). After becoming acclimatised to the planet, Nirgal realises that he has rapidly developed a strong desire to inhabit "a home place that had something like these tile roofs, these stone walls, here and solid these last thousand years" (Robinson, Blue Mars, 192). 
In contrast, on Mars his life has consisted of his "home town [being] crushed under a polar cap $[. .$.$] and every place since then had been just a place, and$ everything everywhere always changing" (Robinson, Blue Mars, 192). At this point in the Mars Trilogy, Martian life is defined by constant strife and precarity, whereas life on Earth has been defined by stability for near innumerable generations until recently, when climate change has begun to gradually make the planet inhospitable to (post)humans. Nirgal therefore has a desperate urge to experience a truly quotidian social life, which Mars has failed to provide for him, but which Earth too can no longer provide. There is more than a hint of satire here. Earth has, to the Martians, become a planet which is alien, and hence they desire to experience and imaginatively colonise its novelty. Life on Mars seems all too familiar to them. The Martians' desire to see Earth thereby lampoons the readers of the text since-despite occupying the privileged position of being able to experience a largely unspoiled Earth automatically and corporeally - they are currently choosing to spend their time reading a grass-is-always-greener SF novel which — to some extent at least-fetishises the idea of leaving Earth behind for another planet.

Fascinatingly then, despite Mars' being the titular planet of the Robinson's trilogy, when the Swiss Alps are described as a "majestic white range" (Robinson Blue Mars, 190) in the chapter set on Earth, it is one of only two times in the entire Mars Trilogy that the word majestic is used, the other instance being immediately qualified by the word "ludicrous" (Robinson, Blue Mars, 346). By having Nirgal arrive on Earth as a (post)human born on Mars, Robinson is able to depict our own planet through a principally defamiliarised lens and show us how beautiful, breathtaking and appropriate our originary planet already is. Earth's postnatural splendour directly contrasts with all the strife within the Trilogy's narrative which has been provoked as a by-product of the attempts to make Mars inhabitable.

Robinson's Mars Trilogy stresses that our species has appeared "only in the last moment of [Mars's] long history" (Robinson, Red Mars, 13) and thus that the entire timescale on which our species has existed is cosmically insignificant in comparison to planetary timescales. In our own world, Earth's current planetary conditions are unusually attuned to sustaining life, to the extent that — as Raworth states — without (post)human influence the planet's "benevolent conditions would be likely to continue for another 50,00o years due to the unusually circular orbit that Earth is currently making of the sun-a phenomenon so rare that it last happened 400,000 years ago" $(2018,48)$. The more we come to recognise that our complexity as a species and as individuals pales in comparison with the Earth's complexity, the more likely we are to care for the amazing planetary body we inhabit. Thus the Mars Trilogy's true novum should 
not be considered to be Mars, or any of the events or technologies that are created upon it, but Earth, the readers' conception of which the text attempts to defamiliarise in order that they come to care for it anew. Ultimately, Robinson's Mars Trilogy exhibits a cautious_-although satirically tempered-optimism that (post)humanity is capable of realising the importance of the planet it already inhabits and of working to safeguard it.

Written only a decade later, Jeanette Winterson's The Stone Gods uses the Nietzchean motif of eternal recurrence to posit a far more fatalistic assessment of our relationship to our planetary environment. Within the novel, (post)humanity repeatedly becomes technologically developed enough to become an interplanetary species only through environmental necessity. Its (post)humans conceptualise their subsequent planetary exoduses as "only natural." This is deeply ironic, given that the need for "moving on" entirely results from their destruction of the natural (Winterson 2008, 4). Each of the novel's four temporally discrete sections is narrated from the perspective of a character named Billie, who appears to have been metempsychotically reborn in each timeframe. The recursive schema of Winterson's text unequivocally refutes the application of linear conceptions of technological progress in the Anthropocene epoch and instead imagines this new temporality as an era of repeated ecological failure.

The opening of the text focuses upon the (post)human civilisation of Orbus who have been funding "the space mission for hundreds of years," a myopic and fervent global agenda that reveals their preoccupation with escaping their originary planet (Winterson 2008, 5; emphasis mine). Despite assertions that, on the following planet they inhabit, "we'll be more careful. This time we will learn from our mistakes," the "Planet Blue" which the population of Orbus has earmarked for inhabitation is none other than Earth itself, and so it immediately seems inevitable that the enduring planetary symbiosis they seek is fated to elude them once again (Winterson 2008, 7; 74). By depicting climate change as a planetary function common to numerous planets which readily delimits (post)human development, The Stone Gods therefore insinuates that our species needs to constantly find new ways of reminding itself of our planet's significance if it is to avoid the catastrophic mistake of taking it for granted.

The task of fostering effective environmental awareness is not an easy one. Kate Raworth argues in her 2017 work Doughnut Economics for the 
implementation of "economic thinking that unleashes regenerative [industrial] design in order to create a circular-not linear-economy, and to restore humans as full participants in Earth's cyclical processes of life" (2018, 29). Raworth demonstrates that economic policies must - on a global scalerenounce their present telos of GDP growth, and instead adapt towards the realization of "a social foundation of well-being that no one should fall below, and an ecological ceiling of planetary pressure that we should not go beyond," in order to realistically generate and maintain "a safe and just space for all" throughout the coming century (2018, 11, emphasis in original). Yet, as Naomi Klein argues in her 2015 book This Changes Everything, "it's hard to keep [climate change] in your head for very long. We engage in this odd form of on-again-off-again ecological amnesia for perfectly rational reasons. We deny because we fear that letting in the full reality of this crisis will change everything" (Klein 2015, 4). Despite Raworth's having proposed a brilliant and wholesale theoretical solution to the postnaturalisation of the Earth, we are, like the characters of Winterson's novel, far too willing to refuse to confront the issue until we are outright forced to.

The ecological amnesia Klein details is particularly evident in Winterson's novel when the celebrity and child abuser Pink McMurphy claims "Don't blame me, [...] I didn't destroy [Orbus]" (Winterson 2008, 80). He exhibits a plain cognitive bias here, as his defensive tract is predicated upon a tu quoque (you too) fallacy; he presumes that he is exonerated from blame for contributing towards climate change because others are also to blame. As is evidently also the case on Orbus, our contemporary consumerist societies promote individualism at the cost of our capacity to work and think collectively-in this instance, in order to bear the cognitive burden of species-wide threats. Likewise, as Marshall states, because climate change is an unusually gradual variety of existential threat which "carries none of the clear markers that would normally lead our brains to overrule our short-term interests" and hence prompt us to act to mitigate a threat, we tend to "mobilize our own biases to keep it perpetually in the background" (2014, 229).

The Stone Gods strongly implies that Orbus itself was not humanity's originary cosmic locale, but rather that its (post)humans came from a precursor planet too, as members of the crew sent to colonise Planet Blue recount in the form of a tale about the discovery of artefacts on "Planet White [which] shares the sun of Planet Blue" (Winterson 2008, 64). Since Planet Blue is Earth and Planet White is stated to have "an atmosphere that is ninety-seven per cent carbon dioxide" (Winterson 2008, 64) and "carbon dioxide constitutes 97 per cent of the Venusian atmosphere" (Kaufmann III 1978, 369), it is safe to assume that (post)humanity has moved from Venus to Orbus and then back to their 
previous planet's next-door-neighbour within the diegesis of Winterson's text. Winterson's ludic implication is that (post)humanity's civilisational progress is fundamentally recursive: that we move from planet to planet, irrevocably devastating each one with our voracity and short-sightedness, before developing spacecraft adequate to move us to another host planet in just sufficient time to escape annihilation.

The Stone Gods therefore plays on the concept of eternal recurrence, suggesting that (post)humanity is condemned to precipitate its own extinction time after time, in an endless causal loop. Although this may seem flippant, the novel's conceit is rendered at least partially plausible by contemporary scientific theories which suggest that countless species of extraterrestrial life may indeed have brought about their own extinction events. Fermi's paradox, which was proposed by Enrico Fermi in the early 1950s and has since been the subject of sustained scientific enquiry, centres around the mathematically implausible observation that our species has not yet come across any evidence that complex life is extant elsewhere in the universe than on Earth. Vilhelm Verendel and Olle Häggström's answer to Fermi's paradox, in their 2017 research paper "Fermi's Paradox, Extraterrestrial Life and the Future of Humanity," proposes that the disparity between the lack of evidence of extraterrestrial life and its high theoretical probability, given that there are "an astronomical number of exoplanets," is the result of a "Great Filter" which occurs during the processes of technological development that all organisms undergo in order to become capable of departing from their home planet (Verendel and Häggström 2017, 14). Climate change is evidently one such Great Filter. Interpreted in this way, Fermi's paradox becomes a compelling imperative to action on ecological grounds, a call to alter customary consumerism, which means that - as Keith Allaun states in the 2018 article "Fuel For Thought" - "If we continue to make single-use plastics at the same pace [as at present], by 2050 we are going to be dealing with an ocean that has more plastic in it, by weight, than fish".

By the conclusion of The Stone Gods, the planet that (post)humanity has settled is once more ecologically devastated, to the extent that Billie, meeting a person named Alaska, has no referent to determine her namesake and presumes that her name is "perhaps to match the colour code," implying that in her time the American state has been drilled out of existence (Winterson 2008, 206). Likewise, the multinational MORE corporation which had subsumed the political system by growing large enough to take "over the Central Power" on Orbus is soon reincarnated on Earth, coming to exert a monopoly over "every station" of television (Winterson 2008, 71; 231). There is a disparaging amor fati in the way The Stone Gods portrays collective (post)human societies as 
existentially greedy and presumes that we will always revert to type and prize fiscal gain over ecological considerations, perpetually attempting to achieve economic growth purely for the sake of achieving economic growth.

Unfortunately, this novel's misanthropic contentions only seem to have been confirmed by the often insincere and largely fiscally motivated "ecological advances" that have ensued since its publication. In his 2018 article "The Colour of Money," Fred Pearce contends that, following the 2015 Paris Climate Change Agreement, although there has been "a huge upswing of investment in 'green' bonds that profess to finance long-term projects needed to fight against climate change" in the financial sector, these bonds often do not sufficiently discriminate between the technologies in which they invest (36). Purportedly green bonds support hydroelectric technologies, for example, which, despite generating renewable energy, also-according to Pearce- "flood ecosystems, displace thousands of people and spread waterborne diseases" and so have a negative impact on the environment on aggregate $(2018,39)$.

Capitalism and consumerism are anathema to ecological harmony, as The Stone Gods makes apparent through its imagery of "the huge double laserarches [...] giant golden Ms [...], glittering under the sky, adapting to the weather" (Winterson 2008, 31). This passage's defamiliarised depiction of the ubiquitous McDonald's logo suggests that billboards on Orbus have been implanted with a technology which makes them adaptive to the changing weather around them, presumably in order that the company's logo can be glimpsed by potential customers in any light conditions. Such a bathetic use of technology - expending finite energy resources in order to attempt to prospectively increase revenues-demonstrates the dangerous fallacy that our species' priorities should be geared towards economic growth regardless of the resultant impact on the environment.

The Stone Gods emphasises that the near-global predominance of anthropocentric ideologies encourages us always to "want the human story" (Winterson 2008,36 ) and to consider only the short-term and human-related implications of any action. This is because we conceive ourselves to be "The only intelligent life in the Universe [...]. Solitary, privileged" (Winterson 2008, 67). As Pearce states, "The fixation on fast returns makes [capitalism] seemingly illequipped to cope with a long-term problem like climate change" $(2018,36)$; indeed, the (post)humans of Orbus absurdly believe that "Without a doubt, parking is the number-one issue facing the[ir] world" (Winterson 2008, 42). Yet we ourselves - since the lives we are living today will detrimentally impact the everyday lives of future generations of (post)humans - are just as short sighted as the ludicrously ignorant citizens of Orbus who, for instance, are 
unconcerned about pollution levels so long as they can buy the "designer versions" of air-masks (Winterson 2008, 44) -

In his 2017 article "Postmodernism-Posthumanism—Evolutionary Anthropology," Wolfgang Welsch asserts that if environmental sustainability is ever to become prevalent, it will only be able to do so by fostering alternative ideologies which emphasise that "we are inherently worldly beings, deeply rooted in the process of evolution, [...] participants in the process of life, sharing a great many traits with other living beings" (76). As Billie proclaims in The Stone Gods, "Human beings aren't just in a mess, we are a mess." Contemporary (post) human societies ought to pay close attention to Klein's avowal that "the solution to global warming is not to fix the world, it is to fix ourselves" (Winterson 2008, 216; Klein 2015, 279).

Unlike in the diegetic world of Winterson's novel, we do not yet possess any reliable means of interstellar travel. Even though a 2018 research paper by Bruce M. Jakosky and Christopher S. Edwards, titled "Inventory of $\mathrm{CO}_{2}$ Available for Terraforming Mars," suggests that it will be impossible to terraform Mars in the "foreseeable future" (638), once we enter the stage of runaway global warming there will simply be no option for our "beginning again differently" by relocating to a nearby planet (Winterson 2008, 39). As Winterson's novel implies through its recursive temporal schema, in the Anthropocene readers need to work fast to take care of the planet they currently inhabit if they are to avoid their impending extinction which — unlike in The Stone Gods - they will be unable to escape by means of a planetary exodus.

3

\section{The Book of Strange New Things}

Released seven years later, Michel Faber's The Book of Strange New Things approaches the challenges of the Anthropocene in a different manner; but it is ultimately just as apocalyptic. The dire effects of climate change occur increasingly rapidly as the novel progresses, and so the impact of the Anthropocene on the lives of the novel's characters undergoes an intensification even throughout its relatively short narrative timeframe. The text is set in a time where the 1980s band A Flock of Seagulls are deemed to be "vintage" and Star Wars "antiquated" (Faber 2015, 30; 266). Its depiction of life on Earth in a near-future temporality envisions the ramifications of the prospect that, as Bryan Lovell predicts in his 2011 book Challenged by Carbon, "our dependence on fossil fuels is likely to persist until $200^{\circ}$ " (148). As the accelerated timescale of apocalyptic events in the novel suggests, the passage of time in the Anthropocene is phenomenologically quickened. 
In The Book of Strange New Things, a minister named Peter leaves his wife Bea behind and travels to Oasis to become an intergalactic missionary, on a planet which is located "in a foreign solar system, trillions of miles from" Earth (Faber 2015, 47). Much of the novel's narrative energy derives from the brief dispatches Peter receives from Bea back on Earth through a "Shoot" - a textbased interface which enables rudimentary communication between the two planets (Faber 2015, 86). Taken as a whole, Bea's messages gesture towards a cataclysmic depiction of a futuristic Earth's being ravaged by anthropogenic climate change, in terms of which it becomes pertinent to dispute Hayles' assertion in her 1996 article "The Life Cycle of Cyborgs" that, since "the human as a concept has been succeeded by its evolutionary heir[,] Humans are not the end of the line" $(2016,247)$. Rather, as things currently stand, we may very well be.

Although the novel's second section is titled "ON EARTH," its narrative only ever depicts Earth by proxy after Peter first leaves it. Yet the near-apocalyptic events occurring back on Earth hold immense significance within the text's overarching plot (Faber 2015, 179). The final message Bea sends to Peter, for example, begins, "Peter, I love you. But please, don't come home. I beg you. Stay where you are" (Faber 2015, 575), a message made terrifying by its evocative yet dire concision and by its choice to leave many of the latest tragedies occurring back on Earth purely to the reader's - and Peter's - imagination. Faber's implication seems clear. Given that — as Thomas L. Friedman states in his 2008 book Hot, Flat, and Crowded - the superficial promotion of climate awareness within contemporary societies lies "out of all proportion to the time, energy, and effort going into designing a systemic solution" to the root causes of ecological crisis, it is likely that the catastrophic imagery of The Book of Strange New Things is soon to become an everyday reality outside of the realm of fiction (206).

Whilst the novel's principal SFnal nova occur through Peter's evangelistic attempts to convey the Christian Gospel to the thoroughly unfamiliar Oasans, these same nova are undergirded by the recurrent interposition of transmissions from an Earth upon which the mundane is fast becoming equally unfamiliar. The first transmission Peter receives from Bea after arriving on Oasis includes an ostensibly mundane aside about the weather, which "has been terrible since [he] left. Heavy downpours every day. [...] There's been flooding in some towns in the Midlands, cars floating down the street, etc. We're OK except that the toilet bowl is slow to drain after a flush, ditto the plughole in the shower cubicle" (Faber 2015, 94). Bea reports this recent spell of unsavoury weather in a matter-of-fact tone and seems less concerned about its palpable - presumably temporary -impact on society than she is about its minor impact on her own familiar, suburbanite existence. 
Since spats of bad weather themselves would appear not to be that far out of the ordinary, they are not notable enough to become a cause for concern or sustained reflection, unlike Bea's drainage situation, which is evidently a perturbing inconvenience for her. As Haydn Washington and John Cook state in their 2011 book Climate Change Denial, the reticence of (post)human societies to recognise the gradually escalating effects of "Climate change has now got to the point where the elephant is all but filling the room. We may now talk about it, but we still deny it" (3). If, as the 2017 Renewables Global Futures Report worryingly asserts, there "appears to be no common view on the role that renewables will play in 2050 amongst experts from the conventional and renewables industries, the scientific community and policy makers," this is at least partially due to the difficulty of conceiving that incremental — and hence primarily irritating — changes in local weather systems are symptomatic of just the beginning of a far wider-reaching anthropogenic planetary crisis (27).

When Bea chastises Peter that "You just don't seem to appreciate how fast and how frighteningly and how MUCH things have changed" (Faber 2015, 428), her frenzied proclamation warns of the drastic disruption and strife that future generations of (post)humans will almost undoubtedly have to undergo on a habitual basis, since-as Daniel J. Fiorino states in his 2018 book Can Democracy Handle Climate Change? - "Much of the impact of climate change already is locked in" (104). As Fiorino emphasises, the onset of anthropogenic climate change is already "all around us, in the form of rising sea levels, intense storms, declining snowpack, costly droughts, heat waves, and worrisome trends in disease patterns" $(2018,104)$. Although many texts within the SF genre anticipate posthuman futures based on the assumption that there will continue to exist a continuum of posthumanity, our species is unlikely to realise such hypothesised further stages of posthuman progression. Like other cli-fi texts, Faber's novel attempts to redress the myopic technophilia exerted by much of the existing body of science fiction.

As of Bea's second Shoot transmission, anthropogenic climate change has become a major component of public consciousness and everyday reality in her society, as is evident by her message's tragic opening, which reveals that "There has been a terrible tragedy in the Maldives. A tidal wave. It was the height of the tourist season. The place was teeming with visitors and it's got a population of about a third of a million. Had. [...] It's one vast swamp of bodies. You see it on the news footage but you can't take it in" (Faber 2015, 126). Whilst tsunamis are not directly caused by climate change, the level of danger they pose to (post)human communities living in low-lying coastal areas such as the Maldives is proportionately exacerbated by sea-level rises. 
Erratic weather continues to intrude further upon Bea's mundane existence, as "blank space" (Faber 2015, 128) begins to gradually overtake supermarket shelves. It becomes progressively harder for Peter to reconcile his wife's traumatic experiences of the increasingly hostile Earth with "his own glad tidings" (Faber 2015, 129) from his missionary successes on Oasis. Every newness in the novel is counterpointed by the obliquely glimpsed impacts of climate change back on Earth. Michel Foucault's prophecy-from his 1966 book The Order of Things - of humanity's being "erased, like a face drawn in sand at the edge of the sea" rapidly becomes identifiable in terms that exceed the merely theoretical $(2003,422)$.

Bea's third communication is shorter and shows evidence that adverse living conditions have become her new normality, as is indicated by the parenthetical (and hence less notable) portion of the sentence "I really must go now and have a shower (assuming the plumbing hasn't gone bung again)" (Faber 2015, 158). Bea's weary aside seems to corroborate Wallace-Wells' prediction that "In a four-degree-warmer world, the earth's ecosystem will boil with so many natural disasters that we will just start calling them 'weather"' (2019, 78). Although Klein argues that the inciting moment for environmental awareness may be brought about by any one major natural disaster, as "the world tends to look a little different when the objects we have worked our whole lives to accumulate are suddenly floating down the street" (465), our species' proficiency in coming to terms with what was previously alien should not be underestimated. Somewhat predictably then, Bea's fourth message to Peter first confirms that "The Maldives tragedy has dropped out of the media," before it discloses that in the UK “The rain was ridiculous, it didn't let up for five hours, full pelt. There were torrents flowing along the footpaths; the drains just aren't designed to take that kind of volume" (Faber 2015, 173; 174). Bea's new "normal" standards of weather, and hence the conditions of (post)human existence, are fundamentally abnormal by prior standards.

Washington and Cook note that "Historically, fear of change probably made sense, as change was often bad news. However, today the change is happening whether we like it or not, due to our actions" and inactions in everyday (post) human life $(2011,90)$. Although the mundane activities we undertake from dayto-day appear ephemeral in nature, their daily enactment has a lasting impact on our planet. Bea's eleven successive communications are far more ominous in tone. One of these messages reads "things are falling apart fast. [...] In our local supermarket there are apology stickers on most of the shelves, empty spaces everywhere. $[. .$.$] The news says that the supply problems are due to the chaos$ on the motorways because of the earthquake in Bedworth a few days back" 
(Faber 2015, 233). The inability of this supermarket to locate an alternate supplier is emblematic of our species-wide unwillingness to adjust our established routines in times of crisis, a behaviour which extends beyond the personal sphere. Wallace-Wells asserts that typically "we assume climate change will hit hardest elsewhere, not everywhere" (Wallace-Wells 2017). Although having to significantly alter our familiar practices to avert ecological catastrophe is never going to be a popular choice, we must come to recognise, as Klein contends, that beliefs "that we can solve the climate crisis without having to change our lifestyles in any way" are deeply flawed (Klein 2015, 232).

Bea reports that "A large chunk of North Korea was wiped out a few days ago. Not by a nuclear strike, or even a nuclear accident, but by a cyclone called Toraji. [...] It was surreal" (Faber 2015, 238). Soon after, "the snow leopard is extinct," Tesco has "gone bust," a "volcanic eruption has destroyed one of the most densely populated cities in Guatemala," and "Some of the wealthiest people in America were murdered [...] dragged out of their homes and beaten to death" (Faber 2015, 250; 337; 354; 355). The rate at which these successive cataclysmic events impact (post)human society, coupled with their indiscriminate nature, make Bea's reports truly horrifying. Peter eventually becomes so perturbed by Bea's communiqués that he begins to feel "feverish and dehydrated" after reading her messages, and hallucinates a voice shouting "WHAT THE FUCK ARE YOU DOING?," which admonishes him for being separated from the disastrous events unfolding back on Earth (Faber 2015, 357; 358). This yelled invective also vicariously implicates the readers in Peter's guilt, provoking them to interrogate their own modes of interaction with their host planet and to seek modes of reparation. The calamitous progression of Faber's novel towards its dire conclusion dramatises the drastic acceleration of planetary history in the Anthropocene.

Published a year later than Faber's novel, Paolo Bacigalupi's The Water Knife takes a more direct approach to depicting the acceleration of planetary history upon (post)humanity. Whereas Faber's novel narrated the catastrophic impacts of the Anthropocene through Shoot transmissions, Bacigalupi's narrates them firsthand, and in a near-future American context. While the preceding texts analysed within this study mediated the cataclysmic impacts of climate change through intergalactic lenses, and so symbolically distanced that impending temporality from the readers' own, The Water Knife depicts the imminent collapse of (post)human society firsthand and in gruesome detail. 
In the novel's Mundane SF milieu-an established SF subgenre which explicitly situates its SFnal nova within the otherwise recognizable fundaments of contemporary life-Arizona's water reserves have run out, not only because its inhabitants "hadn't been able to see something that was plain as day, coming straight at them," but also because regional climate change has contributed to water supplies having become unreliable (Bacigalupi 2016, 113). The narrative of the text accordingly centres around a violent contestation among California, Arizona and Nevada over the rights to the waters of the Colorado River. Having become even more besieged by drought than they are in our contemporary world, the westernmost states of America have begun to contest the ownership of this river by acts of political sabotage. Texas, meanwhile, has already become all but uninhabitable; there are massive numbers of Texan refugees dispersed across the other beleaguered Western states as a result. The novel follows the lives of Angel, a hitman working for the state of Nevada; Lucy, a journalist based in Arizona; and Maria, an opportunistic refugee from Texas - as each of them attempts to survive day-to-day within the drought-stricken city of Phoenix, Arizona.

The (post)human technological mundane has been ruptured; the (post)humans of the novel's diegesis are far more preoccupied with securing and preserving reliable sources of water for themselves than with utilising any ancillary form of technology. The corresponding rupture of Lucy's society is evident in the disparity between the bucolic character of her webchat call to her relatives in "green safe" Vancouver and the house from which she is calling in Arizona, where "A truck idle[s] in the alley behind [her] house, a predatory gasoline growl. It had been rumbling outside for ten minutes and didn't seem to be leaving" (Bacigalupi 2016,$76 ; 74$ ). The call seems tantalisingly to leave the "two realities separated only by a thin wafer of computer screen" (Bacigalupi 2016, 76).

As an SF text, The Water Knife deploys a number of near future nova, including: "data glasses" (Bacigalupi 2016, 347) that appear to be able to store and retrieve information on the object of their gaze in real time; the "Clearsac" (Bacigalupi 2016, 91) which filters the toxins out of urine so that its user can imbibe the precious water from it that would otherwise be lost to the ground; and portable sources of "medical growth stimulant" which vastly improve recovery times from injuries (Bacigalupi 2016, 419). And yet these nova are part of such a nightmarishly-mundane social reality that their novelty seems irrelevant; they scarcely make an impact on the novel's narrative. This, then, is a world where the (post)human fixation on technology has become decentered in favour of a now-mandatory fixation on the essential components of (post) human sustenance. 
Whilst the Phoenix Development Board's promotional material for the Phoenix Rising campaign envisions "a picture of a fiery bird spreading its wings behind a collage of laughing children," just beneath "the billboard a security squad [armed with] M-16s" are herding the same civilians meant to be living in a city resurgent in fortune into waiting vehicles (Bacigalupi 2016, 123). In a world where corporate and political ideologies have become utterly irreconcilable with social reality, life has come to be starkly defined by water consumption, as is apparent when Maria states that "it made her nervous, staring at that pile of water they'd scored. Knowing the days of life it would support. Knowing that people would be inspired to just take it from her" (Bacigalupi 2016, 90). Water is no longer a natural resource but a precious commodity; any engagement with it is just as starkly necessary as it is deeply perilous. The Water Knife's near future vision is terrifying precisely because, as Wallace-Wells states in his 2017 article "The Uninhabitable Earth," "absent a significant adjustment to how billions of humans conduct their lives, parts of the Earth will likely become close to uninhabitable, and other parts horrifically inhospitable, as soon as the end of this century."

At a refugee settlement which characters in the novel visit, "Pure Life and Aquafina and CamelBak had set up relief tents. Getting good PR photos of how they cared for refugees," their underlying motive is opportunistic rather than altruistic (Bacigalupi 2016, 101). And yet, corporate interests and environmentally friendly policy can co-exist. As Fiorino states, "climate action delivers ecological, health, economic, and social benefits" when carefully enacted (2018, 97). In his 2014 book Feral, George Monbiot outlines the benefits, for example, of a project which will "reintroduce the complexity and trophic diversity in which our ecosystems are lacking" by allowing the range of species that constitute native wildlife to repopulate in less intensely postnatural conditions (117). Monbiot concludes that the reintroduction of wolves to the Scottish Highlands would actually make estates "more profitable" by outsourcing the (post) human labour and resources necessary to regulate large populations of deer to their natural predator $(2014,116)$. Likewise in The Water Knife, many animals are managing to thrive even whilst (post)humanity finds itself in a state of catastrophe; when they need to find water "They'd smell it, anyway. Animals are better at this stuff than we are. Human beings, we're stupid in comparison to a coyote" (Bacigalupi 2016, 114). As Monbiot emphasises, "The planet was, before its foodwebs were broken up, controlled by animals and plants [and so] the earth functions as a coherent and self-regulating system" outside of (post) human influence; we are the prime factor that prevents life on our planet from operating in an autopoietic manner $(2014,242)$. The extent of (post)humanity's stupidity is apparent once more when, after waking in a wealthy suitor's 
apartment, Maria is amazed that when she turns on the shower "More water than all of her score at the Red Cross pump gushed down her body and disappeared down the drain" (Bacigalupi 2016, 214). In the novel, climate change has only perpetuated and worsened extant inequalities, even whilst the social mundane of the wealthy has continued unabated. Maria's suitor is like many of us; he truly does not "realize the magic of his life," a life sustained by an abundance of everyday conveniences which are taken entirely for granted (Bacigalupi 2016, 216).

As Erik Bichard realises in his 2014 book The Coming of Age of the Green Community, "The social implication of [climate change] will be that the vulnerable and the less well-off will suffer first and disproportionately [but that] Ultimately everyone will suffer as the fabric of society unravels." Bourgeois individuals cannot feel themselves exempt from the coming repercussions of (post)humanity's detrimental impact on our host planet (120). In The Water Knife, Lucy discovers that regardless of "all the statistics of people displaced by tornadoes and hurricanes and swamped coastlines, these piled corpses [...] struck [her] more forcefully" (Bacigalupi 2016, 135). By depicting the novel's apocalyptic near-future temporality so vividly and urgently, Bacigalupi's pessimistic, even tragic narrative has the same diegetic effect on the reader as the piled corpses do on Lucy.

As the analysis herein has demonstrated, our species' collective lack of progress towards a position closer to symbiosis with our planetary environment over the last three decades is both shocking and perilous. Robinson's Mars Trilogy is critical, yet hopeful, about the propensity of our species to adapt; Winterson's The Stone Gods is significantly more ludic, misanthropic and fatalistic; Faber's The Book of Strange New Things implies the urgency of the need for change in the present; even more desperately, Bacigalupi's The Water Knife brings its apocalyptic vision to bear on an America we can all recognise. Although The Water Knife bears a degree of similarity to Robinson's Mars Trilogy in the sense that they both effectively attempt to compel their readers to modify the manner by which they interact with the planet they live on, there lies a lingering sense, in the intervening twenty years between their respective publications, that the battle might already have been lost. The temporal logic of the Anthropocene which these texts collectively depict is characterised by a claustrophobic sense of catastrophe; they expose the extent to which the future gradually becomes an increasingly precarious territory. 
This article has demonstrated that these four representative cli-fi texts-particularly when read as constituent pieces of a larger subgeneric movement-bear important reflections regarding the position of our species in the Anthropocene epoch. They are texts that break new ground from the largely technophilic canon of SF which precedes them; they attempt to redirect the posthuman dream of the genre away from technological progress and towards the environmental considerations we all need to make in the present if our species is to have a future. In order to investigate whether these findings can be extrapolated more widely within the cli-fi subgenre, the extent to which other cli-fi texts fit this model must be the subject of further critical enquiry. Since this article is entirely focused on cli-fi from the Western Anglophone context, cli-fi from other literary traditions across the Earth must also be a focus for future research in the field. As demonstrated by the cli-fi texts that this article has analysed, (post)humanity must either rapidly and comprehensively rethink the nature of its position on-and responsibilities towards - our already postnatural planet, or we will soon have to confront our own extinction. Either way, however, we will need to fully come to terms with the grim fatalism of Suvin's avowal that “we and our ideologies are not the end product history has been laboring for from the time of the first saber-toothed tigers and Mesopotamian city-states" (1980, 83).

\section{References}

Allaun, Keith. "Fuel For Thought: How To Transform Waste Plastic" Global Cause.

8 June 2018. http://www.globalcause.co.uk/plastic/fuel-for-thought-how-to-trans form-waste-plastic.

Bacigalupi, Paolo. The Water Knife. London: Orbit, 2016.

Bichard, Erik. The Coming of Age of the Green Community: My Neighbourhood, My Planet. London: Routledge, 2014.

Crutzen, Paul J. and Eugene F. Stoermer. "The 'Anthropocene" IGBP Newsletter 41 (2000): 17-18.

Cudworth, Erika and Stephen Hobden. Posthuman International Relations: Complexity, Ecologism and Global Politics. London: Zed Books, 2011.

Faber, Michel. The Book of Strange New Things. Edinburgh: Canongate, 2015.

Fiorino, Daniel J. Can Democracy Handle Climate Change? Cambridge: Polity, 2018.

Foucault, Michel. The Order of Things: An Archaeology of the Human Sciences. London: Routledge, 2003.

Friedman, Thomas L. Hot, Flat, and Crowded: Why the World Needs a Green RevolutionAnd How We Can Renew Our Global Future. London: Penguin, 2008. 
Hay, Jonathan. "Quotidian Science Fiction: Posthuman Dreams of Emancipation" Iowa Journal of Cultural Studies 19, 1 (2019): 29-46.

Hayles, N. Katherine. How We Became Posthuman: Virtual Bodies in Cybernetics, Literature, and Informatics. Chicago: The University of Chicago Press, 1999.

Hayles, N. Katherine. "The Life Cycle of Cyborgs: Writing the posthuman" in Science Fiction and Cultural Theory, edited by Sherryl Vint, 247-257. London: Routledge, 2016.

Hicks, Heather J. The Post-Apocalyptic Novel in the Twenty-First Century: Modernity Beyond Salvage. Basingstoke: Palgrave, 2016.

Jakosky, Bruce M. and Christopher S. Edwards. "Inventory of $\mathrm{CO}_{2}$ Available for Terraforming Mars" Nature Astronomy 2, no. 8 (2018): 634-639.

Kaufmann III, William J. Exploration of the Solar System. London: Macmillan, 1978.

Kaveney, Roz. "Science Fiction in the 1970s: Some Dominant Themes and Personalities" Foundation: The Review of Science Fiction 22 (1981): 5-35.

Klein, Naomi. This Changes Everything: Capitalism vs. the Climate. London: Penguin, 2015 .

Kolbert, Elizabeth. The Sixth Extinction: An Unnatural History. London: Bloomsbury, 2014.

Landon, Brooks. "SF Tourism" in The Routledge Companion to Science Fiction, edited by Mark Bould, Andrew M. Butler, Adam Roberts and Sherryl Vint, 32-41. Abingdon: Routledge, 2009 .

$\mathrm{Li}$, Linlin, et al. "A modest $0.5^{-\mathrm{m}}$ rise in sea level will double the tsunami hazard in Macau" Science Advances 4 (2018).

Lovell, Bryan. Challenged by Carbon: The Oil Industry and Climate Change. Cambridge: Cambridge University Press, 2011.

Marshall, George. Don't Even Think About It: Why Our Brains Are Wired to Ignore Climate Change. London: Bloomsbury, 2015.

Monbiot, George. Feral: Rewilding the Land, Sea and Human Life. London: Penguin, 2014.

Morton, Timothy. Hyperobjects: Philosophy and Ecology after the End of the World. Minneapolis: University of Minnesota Press, 2013.

Nayar, Pramod K. Posthumanism. Cambridge: Polity Press, 2014.

Pearce, Fred. "The Colour of Money" New Scientist (23 June 2018): 36-39.

Pell, Richard W. and Lauren B. Allen. "Preface to a Genealogy of the Postnatural" in Land \& Animal \& Nonanimal, edited by Anna-Sophie Springer and Etienne Turpin, 75-101. Berlin: K. Verlag, 2015.

Raworth, Kate. Doughnut Economics: Seven Ways to Think Like a 21st-Century Economist. London: Random House, 2018.

Renewables Global Futures Report: Great Debates Towards 100\% Renewable Energy. Paris: REN21 Secretariat, 2017. 
Robinson, Kim Stanley. Blue Mars. London: HarperCollins, 2009.

Robinson, Kim Stanley. Green Mars. London: HarperCollins, 2009.

Robinson, Kim Stanley. Red Mars. London: HarperCollins, 2009.

Shippey, Tom. Hard Reading: Learning from Science Fiction. Liverpool: Liverpool University Press, 2016.

Suvin, Darko. Metamorphoses of Science Fiction: On the Poetics and History of a Literary Genre. London: Yale University Press, 1980.

Verendel, Vilhelm and Olle Häggström. "Fermi's Paradox, Extraterrestrial Life and the Future of Humanity: A Bayesian Analysis" International Journal of Astrobiology 16, no. 1 (2017): 14-18.

Wallace-Wells, David. "The Uninhabitable Earth, Annotated Edition" NYMag.com. 14 July 2017. http://nymag.com/daily/intelligencer/2017/07/climate-change-earthtoo-hot-for-humans-annotated.html.

Wallace-Wells, David. The Uninhabitable Earth: A Story of the Future. London: Allen Lane, 2019.

Washington, Haydn and John Cook. Climate Change Denial: Heads in the Sand. London: Earthscan, 2011.

Welsch, Wolfgang. "Postmodernism-Posthumanism-Evolutionary Anthropology" Journal of Posthuman Studies 1, no. 1 (2017): 75-86.

Winterson, Jeanette. The Stone Gods. London: Penguin, 2008. 